\title{
Comparison between the conventional method and a portable device for determination of INR
}

\author{
Determinação do INR: comparação entre método convencional e dispositivo portátil
}

André Camacho Oliveira Araújo1, Rodrigo Borges Domingues1, Bonno van Bellen1

\begin{abstract}
Context: Anticoagulation with warfarin is considered the appropriate treatment for venous thromboembolism and other thrombotic pathologies. Regular INR control is required for dosage adjustment and therapeutic control. Use of portable monitoring systems optimizes management of these patients. Objective: To compare INR measurements taken using the portable Coaguchek XS system in capillary blood with the standard laboratory method using venous blood. Method: Fifty-two samples each of venous and capillary blood were collected from nineteen patients on warfarin, who had been admitted to the Hospital da Beneficência Portuguesa de São Paulo, and analyzed using the conventional method and the Coaguchek XS system, respectively. Results: Spearman's correlation coefficient ( $r$ ) for the overall performance of the two methods was 0.978 ( $p<0.0001 ; 95 \% \mathrm{Cl} 0.961-0.988)$. The Kappa measure of agreement for all patients was $76.8 \%$ ( $p<0.001 ;$ IC: $95 \%$ 0.975-0.561). Mean INR according to the Coaguchek XS system underestimated the values provided by the conventional method by -0.01 INR points, with a standard error of 0.342 . Results for INR values greater than 3.5 were satisfactory with a correlation coefficient of 0.71 , but without statistical significance ( $p>0.714$ ). Conclusions: The Coaguchek XS system can be used to monitor prothrombin time in patients on oral anticoagulants, provided INR values greater than 3.5 are confirmed using the conventional laboratory method.
\end{abstract}

Keywords: prothrombin time; blood coagulation; warfarin; venous thromboembolism.

\begin{abstract}
Resumo
Contexto: Anticoagulação por varfarina (warfarin) é considerada tratamento adequado para tromboembolismo venoso e outras patologias trombóticas. Deve ser realizada a mensuração do Índice Internacional Normalizado (INR) para ajuste de dosagem de medicamento para manutenção dos pacientes na faixa terapêutica. O uso de dispositivos portáteis otimiza o controle desses pacientes. Objetivo: Comparar as medidas do INR realizadas pelo sistema portátil Coaguchek XS, em sangue capilar, com o método laboratorial padrão em sangue venoso. Método: Dezenove pacientes em uso de varfarina, internados no Hospital da Beneficência Portuguesa de São Paulo, foram submetidos à coleta de 52 amostras analisadas pelo método convencional e coleta de sangue capilar para medida com o sistema Coaguchek XS. Resultados: $O$ coeficiente de correlação $(r)$ de Spearman por meio da comparação de desempenho global entre os dois métodos foi de 0,978 ( $p<0,0001 ;$ IC: 95\% 0,961-0,988). O percentual de concordância Kappa para todas as faixas foi de 76,8\% ( $<<0,001 ;$ IC: $95 \%$ 0,975-0,561). O INR médio do sistema Coaguchek XS subestimou os valores obtidos em $-0,01$ pontos de INR, quando comparado ao método convencional, com erro padrão de 0,342. Valores acima de 3,5 mostraram resultados satisfatórios com coeficiente de correlação de 0,71, mas sem significância estatística ( $p>0,714$ ). Conclusões: $\mathrm{O}$ sistema Coaguchek XS pode ser utilizado na monitorização do tempo de protrombina em pacientes com uso de anticoagulantes orais, desde que valores de INR acima de 3,5 sejam confirmados por meio de medidas realizadas em laboratório convencional.
\end{abstract}

Palavras-chave: tempo de protrombina; coagulação sanguínea; varfarina; tromboembolismo venoso. 


\section{INTRODUCTION}

Oral anticoagulation with vitamin $\mathrm{K}$ inhibitors, such as warfarin, is an appropriate treatment for venous thromboembolism and other pathologies and is widely used. However, these drugs must be administered with caution because of their narrow therapeutic window. The primary objective of this treatment is to maintain anticoagulation at levels high enough to prevent thromboembolic events, whilst incurring as little hemorrhagic risk as possible.

In clinical practice, the most widely-used test for controlling oral anticoagulation levels is prothrombin time (PT) using the International Normalized Ratio (INR). The INR is a method for calibrating the prothrombin time in order to reduce variation in PT results across different clinical laboratories. The gold-standard method for measurement of INR is laboratory analysis of venous blood samples with coagulation analyzers. For the majority of indications, the ideal INR level to achieve safe and effective anticoagulation lies within the range of 2.0 to $3.0 .1,2$

With the objective of simplifying monitoring of these treatments, portable devices have been developed for use at the point of care to provide an INR measurement using capillary blood samples. These devices are easy to use, provide a rapid result and can be utilized in the home environment by the patients themselves.

There are currently several different devices capable of measuring INR from capillary blood samples, but there is not yet consensus on their accuracy, particularly when INR values are greater than 4.0. In Brazil, the regulatory authority ANVISA has registered two such devices: CoaguChek XS, manufactured by Roche Diagnostic, and i-STAT, manufactured by Abbott.

The primary objective of this study is to compare conventional laboratory testing with de Coaguchek XS to determine its efficacy and safety in patients on warfarin. A secondary objective is to compare the resulting medical decisions that would be taken on the basis of the results of the two methods and the differences between the costs of the conventional method and of the Coaguchek XS.

Although there are publications demonstrating the efficacy of the portable system,3-6 few studies have been conducted into its use in Brazil. The method is little used in this country.7-10

\section{METHODOLOGY}

Patients. This is a cross-sectional study conducted between October 2012 and January 2013. Fifty-two samples were taken for prothrombin time analysis from 19 inpatients on oral anticoagulation.

Inclusion criteria. Patients in hospital and on warfarin whose blood samples underwent prothrombin time analysis with INR in the clinical analyses laboratories at the Hospital da Beneficência Portuguesa de São Paulo.

Exclusion criteria. samples were excluded if problems affected biological material collection.

Determination of PT by the conventional method. $10 \mathrm{~mL}$ venous blood samples were collected into tubes containing 3.8\% sodium citrate solution. Plasma was extracted from the samples by centrifugation at $3,800 \mathrm{rpm}$ for $5 \pm 2$ minutes and then the PT with INR was assayed using an ACL Elite Pro automated coagulation analyzer and a kit containing thromboplastin Recombiplastin $2 \mathrm{G}$ solution with an International Sensitivity Index (ISI) of 1.0.

Determination of PT using the portable test. Samples of capillary blood were taken within one hour of collection of samples for the conventional method. Samples of approximately $10 \mu \mathrm{L}$ were taken by finger stick from the finger pad of the first finger of patients' non-dominant hand, using Accu-Chek Safe-T-Pro Uno lancets. The blood drop was placed onto a Coaguchek XS PT test strip containing human recombinant thromboplastin with an ISI of 1.0 and the device displayed the result in approximately one minute.

Classification of samples. The results for the 52 samples were classified by therapeutic range: INR $<2.0$; INR $2.0-3.5$; or INR $>3.5$.

Ethical approval. The research project was approved by the Research Ethics Committee at the Hospital da Beneficência Portuguesa de São Paulo and all patients indicated their agreement to participation by signing consent forms.

\section{Statistical analysis}

The INR results provided by the two different methods were analyzed for the entire sample and for the three subsets: INR <2.0; INR 2.0-3.5; and INR $>3.5$. The following analyses were performed: Student's t test for paired samples, Spearman's correlation index and the BlandAltman test, for evaluation of the differences between results. A 95\% confidence interval and an $\alpha$ error of $\mathrm{p}<0.05$ for statistical significance were adopted. Microsoft Excel 2007 was used for statistical analysis with the XLSTAT (trial version) and Analyze-it add-ins. 


\section{RESULTS}

The 19 patients were distributed as follows, male: $47.3 \%$, female: $52.7 \%$, age: 33 to 92 years, mean age: 62.6 years. When classified by therapeutic range, $18(34.6 \%)$ samples had INR < 2.0; $24(46.15 \%)$ samples had INR of 2.0-3.5; and $6(11.5 \%)$ samples had INR > 3.5; while four (7.69\%) samples had reading errors and the results were discarded.

Mean INR using the Coaguchek XS system was $2.48 \pm 1.24$, with a minimum of 1.0 , a median of 2.25 and a maximum of 6.8. Mean INR using the conventional method was $2.491 \pm 1.325$, with a minimum of 1.09 , a median of 2.2 and a maximum of 7.95 (Table 1).

Spearman's correlation coefficient (r) for a comparison of the two methods' overall performance was 0.978 with $p<0.0001$ (95\%CI: 0.961-0.988). The coefficients for the three therapeutic ranges defined above were 0.917 with $\mathrm{p}<0.0001$ (95\% CI 0.781$0.970)$; 0.896 with $\mathrm{p}<0.0001$ (95\%CI 0.767-0.956); and 0.71 with $\mathrm{p}<0.714$ (95\%CI - 0.263-0.968) respectively (Table 2 ).

The linear correlation between the results given by each method is illustrated in Figure 1.

According to the Bland-Altman test, the Coaguchek XS system exhibited bias of -0.01 at all levels of measurement, with a standard error of 0.342 (Table 3).

The Bland-Altman plot shows the difference between INR results from the Coaguchek XS system and the control method (Figure 2).

Table 4 shows simple percentage agreement between the Coaguchek XS system and the control method, for each therapeutic range. The Kappa agreement statistic for all ranges was $76.8 \% \mathrm{p}<0.001$ (95\% CI 0.975-0.561).

There were data collection errors involving four $(7.62 \%)$ of the total of 52 samples tested using the portable machine. The data from these samples with errors were excluded. In three $(75 \%)$ cases the error message indicated that the quantity of blood was insufficient and there was a test error in one $(25 \%)$ case.

\section{DISCUSSION}

Oral warfarin anticoagulation exhibits significant variations between the dose administered and the effective therapeutic dose, meaning that constant monitoring of prothrombin times is necessary for patients on this medication.

The development and continuous improvement of portable devices for INR control offers significant advantages for patient management. It is most important to choose a reliable and precise system for this purpose.

The Coaguchek XS system is the third generation of devices produced by Roche Diagnostics for portable INR monitoring. The first Coaguchek model was launched in 1994, followed by the CoaguChek $\mathrm{S}$ in 2000. The latest generation of monitors was launched in 2006 with the CoaguChek XS device. The monitor meets the requirements of European Union guidelines and recommendations and was approved in February 2007 by the United States Food and Drug Administration, responsible for regulating

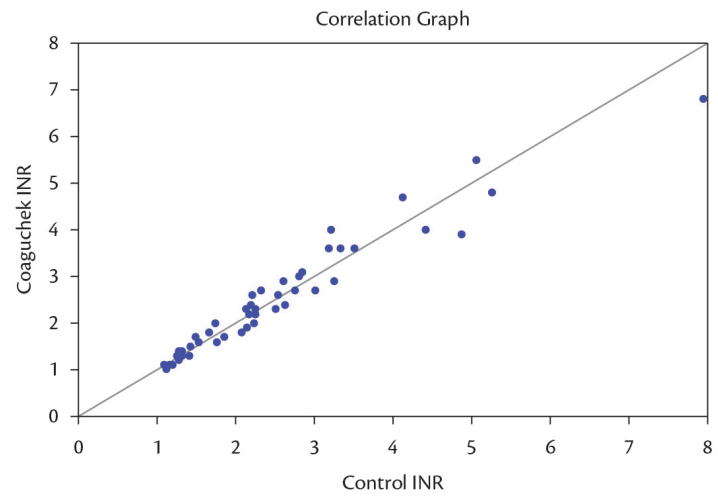

Figure 1. Correlation. R $0.978 \mathrm{p}<0.0001$ ( $95 \% \mathrm{Cl} 0.961-0.988$ ).

Table 1. Means of INR results.

\begin{tabular}{cccccc}
\hline Variable & Number of samples & Minimum & Maximum & Mean & 2.491 \\
\hline Control INR & 48 & 1.090 & 7.950 & 6.800 & 2.481 \\
Coaguchek INR & 48 & 1.000 & 6.325 & 1.242 \\
\hline
\end{tabular}

Table 2. Spearman correlation coefficients.

\begin{tabular}{cccc}
\hline INR Category & $\mathrm{N}$ & Spearman Coefficient & $p$ \\
\hline$<2$ & 18 & 0.917 & $<0.0001$ \\
$2.01-3.5$ & 24 & 0.896 & $<0.0001$ \\
$>3.51$ & 6 & 0.71 & $<0.714$ \\
Mean of all categories & 48 & $0.98<0.0001$ & \\
\hline
\end{tabular}


Table 3. Bland Altman Test.

\begin{tabular}{cccc}
\hline INR Category & N & Bias & $\begin{array}{c}\text { Standard } \\
\text { error }\end{array}$ \\
\hline$<2$ & 18 & 0.005 & 0.128 \\
$2.01-3.5$ & 24 & 0.058 & 0.292 \\
$>3.51$ & 6 & -0.33 & 0.713 \\
Mean of all categories & 48 & -0.01 & 0.342 \\
\hline
\end{tabular}

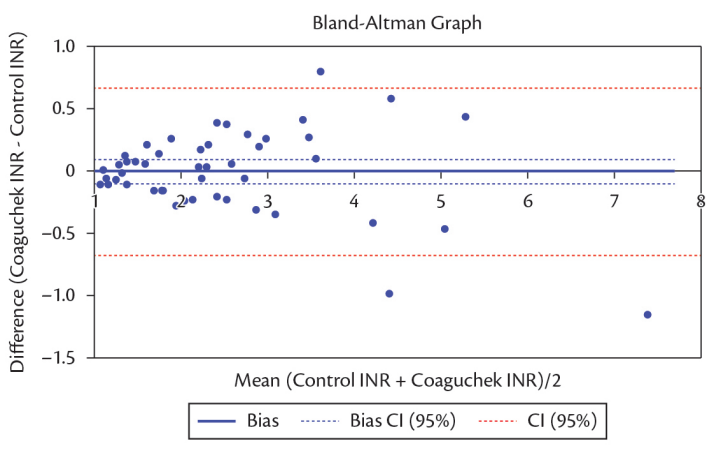

Figure 2. Bland-Altman Plot.

Table 4. Simple percentage agreement by therapeutic ranges.

\begin{tabular}{lllll}
\hline \multicolumn{5}{c}{ INR Coaguchek XS } \\
\hline Control & \multicolumn{1}{c}{ INR $<2$} & INR 2-3.5 & INR $>3.5$ & Total (\%) \\
\hline INR $<2$ & 17 & 1 & 0 & $18(37.5)$ \\
INR 2-3.5 & 2 & 18 & 4 & $24(50)$ \\
INR $>3.5$ & 0 & 0 & 6 & $6(12.5)$ \\
Total (\%) & $19(39.58)$ & $19(39.58)$ & $10(20.8)$ & $48(100)$ \\
\hline
\end{tabular}

food and medicines. It has its approval valid until 2016 from the Brazilian sanitary agency ANVISA.8

Previous studies have already shown that there is good correlation between the Coaguchek XS system and laboratory measurements; but this method for prothrombin time control has been tested little in Brazil.

The first study to report on the performance of the Coaguchek XS portable monitor, published in 2008, analyzed 370 samples and observed 97\% accuracy for variations smaller than 0.5 INR points or $\pm 30 \%$, concluding that the device met the requirements of Chapter 8 of the ISO 17593:2007 quality control standard. The study also reported a reading error rate of $1.5 \%$, which is equivalent to a difference of less than 0.05 of an INR point, when comparing peripheral blood samples and capillary blood samples. The study was sponsored by Roche Diagnostics.3

Spearman's coefficient for the correlation between INR values in the present study was very high at 0.97 with $\mathrm{p}<0.0001$. Correlation coefficients greater than
0.7 indicate strong correlations between two variables and 1.0 is the highest degree of correlation possible. However, according to Bland and Altman, correlation coefficients are not the best method for evaluating two different measurement methods because they only provide information on the variation between the two results and not on the absolute differences. The Bland and Altman test is recommended for samples larger than one hundred.11

Meneghelo et al. conducted a study with 219 INR samples, finding correlation coefficients of 0.91 for INR $<2 ; 0.85$ for INR of $2-3.5$; and 0.71 for INR $>3.5$. The percentage of agreement between the two methods for all ranges was $88.5 \% .7$

According to the Bland and Altman test, the Coaguchek XS system underestimated INR measurements by -0.01 points, with a standard deviation of 0.342 INR points. Additionally, the standard deviation of values increases as INR increases. Measurements over 3.5 were less reliable, but still demonstrated relatively reliable accuracy. The small number of samples with INR greater than 3.5 meant that statistical significance was not achieved in this interval. The lower distribution of patients with INR greater than 3.5 is attributed to the fact that the patients were in hospital and so it was easier to maintain INR within the therapeutic range.

The variable levels of agreement for different therapeutic ranges indicate that the readings of the portable system would lead to a different management in terms of dose adjustment for seven samples $(14.58 \%)$ : the results for two samples $(4.16 \%)$ would have led to a higher dose of warfarin and for five samples $(10.41 \%)$ the resultant dose would have been lower. Variation exceeded 0.5 INR points for four samples $(8.33 \%)$.

Donaldson et al. published a study in 2010 in which they observed that if the Coaguchek XS plus device had been used to take the treatment decision, it would have been different from the decision taken on the basis of the results of the conventional method for $33 \%$ of 52 INR samples from patients on warfarin, while the decision would have been different in 54\% of cases if the i-STAT device had been used.5

Williams et al. published a study in 2007, based on 97 INR samples from patients in a pediatric age group, in which $13 \%$ of cases would have been treated differently if the Coaguchek XS device had been used and reported that $19 \%$ of the samples had variation greater than 0.5 INR points. The study also compared the device with its predecessor (Coaguchek S), observing that it offered greater efficacy and recommending substitution. 6 
In order to facilitate statistical comparison of different studies, therapeutic ranges were chosen to be similar to those employed in other studies involving the Coaguchek XS. It should be pointed out that, in this study, the target therapeutic range for patients on anticoagulation for treatment of venous thromboembolism is an INR of 2.0 to 3.0. The portable device offered greater precision for measurement of values within this interval than for values above or below this range.

Notwithstanding the fact that the device is easy to use and comes with an illustrated manual in Portuguese, we had operational errors with four $(7.62 \%)$ test strips out of the total of 52 samples tested. In three $(75 \%)$ of these cases the error message indicated that the quantity of blood was insufficient and in one $(25 \%)$ case there was a test error. An earlier study reported a much lower error rate, just $1.5 \% .3 \mathrm{We}$ believe that the variation is due to the learning curve related to obtaining the blood sample, since this research project was the occasion of first contact with the equipment. It should be pointed out that, according to the manual, the manufacturer Roche Diagnostics offers a home visit by a trained professional for the purposes of instruction with each device purchased. This training session was not requested by the researchers responsible for this study.

Warfarin is the treatment option for venous thromboembolism that imposes the lowest cost on patients in Brazil because both medication and laboratory control of INR are provided free of charge by the healthcare system, with the cost subsidized by the State. The possibility of selfmanagement of anticoagulation offers benefits in terms of convenience, safety and practicality, which are difficult to measure financially. Of the available options, certain groups should be considered: patients with indications for long-term anticoagulation, patients with difficulties for locomotion and patients with chronic kidney disease, since these conditions restrict the use of other methods.

In the Brazilian market, the current cost of the device to the final consumer is $\mathrm{R} \$ 960.00$ to $\mathrm{R} \$ 1,100.00$. The reagent strips cost $\mathrm{R} \$ 16.00$ to $\mathrm{R} \$ 28.00$ each. Lancets cost R\$ 0.44 to $\mathrm{R} \$ 0.74$. Based on a schedule of two measurements per month with the Coaguchek XS system, and using the lowest prices found, the annual cost was estimated at $\mathrm{R} \$ 1,354.56$.

In view of the high incidence of patients on warfarin, the possibility of acquiring portable devices for primary care health centers that do not have on-site laboratories should be considered. However, the Brazilian national health service (SUS) technology committee (CONITEC - Comissão Nacional de Incorporação de Tecnologias no SUS) did not recommend their use. It should be pointed out that the study conducted by CONITEC calculated the cost of using the portable device for all INR tests conducted by the SUS, including in hospital settings where the infrastructure necessary to conduct conventional testing is available; in other words it did not take into account the demographic distribution of patients in difficult to access regions who would benefit from management using the portable device. 8

In 2011, Heneghan et al. published a metaanalysis of 11 randomized studies investigating self-management of warfarin anticoagulation versus conventional monitoring. The study found evidence of a significant reduction in new thromboembolic events in the self-management group (OR 0.51, 95\% CI 0.31-0.85), but no difference in overall mortality (OR 0.82, 0.62-1.09) or major hemorrhages (OR 0.88, 0.74-1.06). Patients less than 55 years old and on self-management had a significant reduction in new thromboembolic events (OR $0.33,95 \%$ CI $0.17-0.66)$ as did patients with mechanical cardiac valves (OR 0.52, 0.35-0.77). Analysis of data on patients over the age of 85 did not find significant improvements using self-management. The studies reviewed in this analysis employed devices offering lower levels of precision, which were available at the time they were conducted. 12

In 2002, the THINRS Trial found that $80 \%$ of a population of 3,644 individuals were eligible for self-management of anticoagulation, after adequate training. This study did not find changes to the risk of major bleeding or death in the anticoagulation self-management group. 13

In 2012, DeSantis et al. published results from the Alere international database of INR results acquired weekly from the portable devices of patients on selfmanagement regimens. They found that $73.9 \%$ of values were within the therapeutic window, which is superior to the mean of $63.2 \%$ found in six other randomized clinical trials. The possibility should therefore be considered that the ease of measuring INR makes it more likely for patients to remain within their therapeutic ranges for longer periods of time. 14

The 2012 ACCP Guideline recommends selfmanagement of anticoagulation combined with normal outpatients monitoring, with a recommendation level of $2 \mathrm{~B}$, for patients on vitamin $\mathrm{K}$ inhibitors who demonstrate both the motivation and competence 
for anticoagulation self-management, using the portable device. 15

It can be concluded that anticoagulation is improved by self-management, but not all patients are eligible and possible candidates must be identified and trained. Consideration should be given to conducting randomized trials with groups controlling prothrombin time with the conventional method and others using self-monitoring and self-management of anticoagulation, with clinical outcomes related to bleeding, thromboembolic events and time within the therapeutic range, in order to evaluate the safety and effectiveness of this device.

\section{CONCLUSIONS}

On the basis of the results of this study, it is concluded that the Coaguchek XS system could be useful for monitoring prothrombin time and INR in patients on oral anticoagulants, provided results greater than 3.5 INR are confirmed by assays conducted in a conventional laboratory.

It is not possible to state that different treatment decisions taken because of using the portable monitor would lead to increased incidence of thromboembolic or hemorrhagic complications. To determine this, randomized clinical trials are needed.

\section{REFERENCES}

1. Kitchen S, Preston FE. Standardization of prothrombin time for laboratory control of oral anticoagulant therapy. Semin Thromb Haemost. 1999;25:17-26. PMid:10327216. http://dx.doi. org/10.1055/s-2007-996419

2. Hirsh J, Dalen JE, Anderson DR, et al. Oral anticoagulants: mechanism of action, clinical effectiveness, and optimal therapeutic range. Chest. 1998;114(Suppl):445S-469. PMid:9822057. http:// dx.doi.org/10.1378/chest.114.5_Supplement.445S

3. Plesch W, Wolf T, Breitenbeck N, et al. Results of the performance verification of the Coaguchek XS system. Thromb Res. 2008;123(2):381-9. PMid:18585761. http://dx.doi. org/10.1016/j.thromres.2008.04.021

4. Connock M, Stevens C, Fry-Smith A, Jowett S, Fitzmaurice D, Moore D. Clinical effectiveness and cost-effectiveness of different models of managing long-term oral anticoagulation therapy: a systematic review and economic modeling. Health Technol Assess 2007;11(38):iii-iv-ix-66.

5. Donaldson M, Sullivan J, Norbeck A. Comparison of international normalized ratios provided by two pointof-care devices and laboratory-based venipuncture in a pharmacist-managed anticoagulation clinic. Am J Health System Pharm. 2010;67(19):1616-22. PMid:20852163. http://dx.doi. org/10.2146/ajhp100096

6. Williams VK, Griffiths AB. Acceptability of Coaguchek S and Coaguchek XS generated international normalized ratios against a laboratory standard in paediatric setting. Pathology. 2007;39(6):575-9. PMid:18027261. http://dx.doi. org/10.1080/00313020701684797
7. Meneghelo ZM, Liporace IL, Nunes PP, et al. Comparação dos níveis do tempo de protrombina, obtidos pelo monitor portátil CoaguChek XS e técnica padrão, em pacientes ambulatoriais usando anticoagulante oral. Instituto Dante Pazzanese de Cardiologia; 2009. Não publicado.

8. Comissão Nacional de Incorporação de Tecnologias no SUS - CONITEC. Coaguchek XS no monitoramento do INR em pacientes recebendo tratamento com varfarina. Ministério da Saúde; 2012. www.saude.gov.br/sctie.

9. De Piano LPA, Strunz CMC, Mansur ADP, Rached RA. Comparação entre os resultados do índice de normalização internacional medidos em dispositivo portátil (Hemochron)r.) e por metodologia convencional. Arq Bras Cardiol. 2007;88(1):31-34. PMid:17364115. http://dx.doi.org/10.1590/\$0066-782X2007000100005

10. Leiria TLL, Pellanda LC, Magalhães E, Lima GG. Controle do tempo de anticoagulação oral: correlação e concordância. Arq Bras Cardiol. 2007;89(1): 1-5. PMid:17768575. http://dx.doi. org/10.1590/S0066-782X2007001300001

11. Bland JM, Altman DG. Measuring agreement in method comparison studies. Stat Methods Med Res. 1999;8(2):135-60. http://dx.doi.org/10.1191/096228099673819272

12. Heneghan C, Alison W, Rafael P. The self-Monitoring Trialist Collaboration. Self-monitoring of oral anticoagulation: a systematic review and meta-analysis of individual patient data. Lancet. 2011. http://dx.doi.org/10.1016/S0140-6736(11)61294-4

13. David BM, Alan J, Rowena D, et al. THINRS Trial: Effect of Home Testing of International Normalized Ratio on Clinical Events. New Engl J Med. 2010;363:17.

14. DeSantis G, Hogan-Schlientz J, Liska G, et al. Real-world weekly INR Testing of 4,550 patients. ACC 2012; abstract \#12-A9012-ACC.

15. Anne H, Sam S, Daniel MW, et al. Evidence-based management of anticoagulant therapy: antithrombotic therapy and prevention of thrombosis, 9th ed: American College of Chest Physicians evidencebased clinical practice guideline. Chest. 2012;141:e152S-e184S.

Correspondence
Bonno van Bellen
Rua Maestro Cardim, 925 - Liberdade
CEP 01323-001 - São Paulo (SP), Brazil
Tel.: (11) 998432-8513
E-mail: bellen@apm.org.br
Author information
ACOA e RBD são Estagiários do Serviço de Cirurgia Vascular
Integrada do Hospital da Beneficência Portuguesa de São Paulo.
Bvi é Professor Livre-Docente em Moléstias Vasculares Periféricas,
Chefe do Serviço de Cirurgia Vascular Integrada do Hospital
da Beneficência Portuguesa de São Paulo e Membro Titular de
Sociedade Brasileira de Angiologia e Cirurgia Vascular.
Author contributions
Conception and design: ACOA, BvB
Analysis and interpretation: ACOA, RBD, BvB
Data collection: ACOA
Writing the article: ACOA, BvB, RBD
Critical revision of the article: BvB
Final approval of the article: ACOA, RBD, BvB
Statistical analysis: ACOA
Overall responsibility: BvB
Financial support: None.

